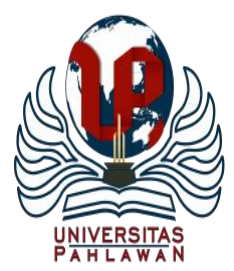

Jurnal Abdidas Volume 2 Nomor 1 Tahun 2021 Halaman 53-58

JURNAL ABDIDAS

http://abdidas.org/index.php/abdidas

\title{
Aplikasi Penunjang Pembelajaran Berbasis TIK dengan Memanfaatkan SEVIMA Edlink di SMPIT Insan Rabbani
}

\author{
Winda Suci Lestari Nasution ${ }^{\bowtie}$ \\ Universitas Esa Unggul, DKI Jakarta, Indonesia \\ E-mail : winda.suci@esaunggul.ac.id
}

\begin{abstract}
Abstrak
Pandemi Covid-19 yang melanda dunia telah memberikan efek yang luar biasa kepada kehidupan. PSBB (Pembatasan Sosial Berskala Besar) yang dilanjutkan dengan WFH (Work From Home) dan juga pembelajaran daring adalah konsekuensi dari pandemi Covid-19. Kemajuan yang sangat pesat di dunia teknologi informasi yang dipicu oleh internet dan ponsel pintar telah mengubah semua aspek kehidupan manusia yang mengarah ke kehidupan digital. Pengetahuan dan kemampuan guru SMPIT Insan Rabbani dalam penggunaan dan pemanfaatan teknologi informasi dan komunikasi (TIK) khususnya SEVIMA EdLink masih kurang. SEVIMA EdLink sebagai pendukung pembelajaran online yang menyesuaikan dengan kebutuhan pada era digitalisasi untuk menghasilkan keterampilan guru dan siswa-siswa sebagai tenaga kerja yang terampil dan berkeahlian yang mampu menyesuaikan dari tuntutan dan kebutuhan pembelajaran berbasis IT dengan mempertimbangkan nilai-nilai antara lain nilai ekonomis, nilai fungsional, nilai psikologis dan nilai kreatif dan nilai inovatif. Hasil yang diperoleh adalah guru dapat menyampaikan bahan ajar, membuat tugas serta ujian kapanpun dan dimanapun.
\end{abstract}

Kata kunci: pembelajaran daring, pemanfaatan teknologi informasi dan komunikasi (TIK), SEVIMA Edlink

\begin{abstract}
The Covid-19 pandemic that has hit the world has had tremendous effects on lives. PSBB (Large-Scale Social Restrictions) followed by WFH (Work From Home) and also online learning are the consequences of the Covid-19 pandemic. The very rapid progress in the world of information technology which is triggered by the internet and smart phones has changed all aspects of human life that lead to digital life. The knowledge and abilities of SMPIT Insan Rabbani teachers in the use and utilization of information and communication technology (ICT), especially SEVIMA EdLink, are still lacking. SEVIMA EdLink as a support for online learning that adapts to the needs of the digitalization era to produce the skills of teachers and students as a skilled and skilled workforce that is able to adapt to the demands and needs of IT-based learning by considering values including economic value, functional value, psychological value and creative value and innovative value. The results obtained are that the teacher can deliver teaching materials, make assignments and exams anytime and anywhere.
\end{abstract}

Keywords: online learning, use of information and communication technology (ICT), SEVIMA edlink

Copyright (c) 2021 Winda Suci Lestari Nasution

$\triangle$ Corresponding author

Address : Universitas Esa Unggul

Email : winda.suci@esaunggul.ac.id

ISSN 2721- 9224 (Media Cetak)

DOI $:$ https://doi.org/10.31004/abdidas.v2i1.202

ISSN 2721- 9216 (Media Online)

Jurnal Abdidas Vol 2 No 1 Tahun 2021 p-ISSN 2721-9224 e-ISSN 2721-9216 


\section{PENDAHULUAN}

Pendidikan merupakan hal yang paling penting dalam membangun suatu bangsa. Melalui pendidikan maka seseorang dapat memajukan dan mengembangkan segala potensi yang dapat memberikan kemakmuran sebuah bangsa. Pendididkan diberikan sejak kecil kepada seseorang dimulai dari Taman Kanak-kanak hingga tingkat Sarjana sesuai dengan bakat dan potensinya. Perkembangan teknologi yang berkembang juga sangat memberi andil dalam perkembangan kualitas pendidikan sehingga mampu mendukung proses pembelajaran di Indonesia terutama dari sisi Teknologi dan Informasi (Al Zukri, Asynari, and Jatmiko 2020).

Perkembangan teknologi informasi dan komunikasi saat ini mengalami perubahan dan perkembangan yang sangat pesat. Banyak inovasiinovasi baru diberbagai bidang mulai dikembangkan dan terlibat dalam inkubator teknologi seperti bisnis, industri, pertanian, kesehatan, dan tanpa terkecuali pendidikan khususnya, dalam penyedia media proses pembelajaran. Sudah banyak sekali yang menciptakan software media pembelajaran untuk mempermudah dalam proses belajar mengajar (Arifin 2013). Sekolah Islam Terpadu (SIT) Insan Rabbani merupakan lembaga pendidikan Islam yang berorientasi pada pembentukan karakter SMART (Sholeh, Mushlih, Cerdas, Mandiri Dan Terampil) bagi peserta didiknya. Pandemi Covid19 yang melanda dunia pada umumnya dan juga Indonesia pada khususnya telah memberikan efek yang luar biasa kepada kehidupan. PSBB (Pembatasan Sosial Berskala Besar) yang dilanjutkan dengan WFH (Work From Home) dan juga pembelajaran daring adalah konsekuensi dari pandemi Covid-19 (Kharisma, Roesminingsih, and Suhanadji 2020). Disisi lain kemajuan yang sangat pesat di dunia teknologi informasi yang dipicu oleh internet dan ponsel pintar telah mengubah semua aspek kehidupan manusia yang mengarah ke kehidupan digital. Terlihat para guru di Sekolah Insan Rabbani masih mengalami kesulitan saat mengalihkan metode KBM yang semula tatap muka menjadi KBM daring. Oleh karena itu dirasa perlu adanya pendampingan buat para guru dalam mempersiapkan materi ajar menjadi materi ajar daring.

Peran perguruan tinggi melalui Tri Dharma Perguruan Tinggi adalah melaksanakan pendidikan, penelitian dan pengabdian kepada masyarakat. Salah satu bentuk kewajiban dan kepedulian tersebut adalah pelaksanaan pengabdian kepada masyarakat melalui pendampingan kepada para guru dalam mempersiapkan materi pembelajaran daring.

Program Kegiatan ini dimaksudkan untuk mengimplementasikan sistem kemitraan dalam memfasilitasi pemahaman konsep aplikasi SEVIMA EdLink. Seperti penelitian terdahulu didapatkan hasil bahwa SEVIMA Edlink yang ditelaah dengan menggunakan teori Sections dan Chaple bahwa SEVIMA Edlink ini sangat direkomendasikan untuk dijadikan sebagai media elektronik pada pembelajaran (Wibowo and Rahmayanti 2020). Penelitian kedua juga dilakukan oleh (Marlina 2020) menghasilkan kesimpulan bahwa pembelajaran menggunakan SEVIMA Edlink cocok digunakan dalam mata pelajaran matematika didalam mengembangkan pembelajaran merdeka di kampus 
Merdeka. Adapun tujuan yang ingin dicapai dari dilaksanakan pelatihan dan keterampilan yaitu solusi yang diperlukan yaitu pemberian pelatihan dengan metode training secara praktis melalui transfer ilmu dan praktek langsung pada aplikasi SEVIMA EdLink diharapkan tercapainya kemampuan yang merata dalam pemahaman aplikasi SEVIMA EdLink sebagai pendukung pembelajaran online guna meningkatkan dan menambah pengetahuan dan kemampuan para guru dan siswa dalam pemanfataan aplikasi SEVIMA EdLink khususnya dalam penyampain materi bahan ajar selama masa pandemik ini. Untuk jenis luaran yang dapat dirasakan adalah meningkatkan pemahaman dan kemampuan secara praktis tentang kegunaan dari SEVIMA EdLink sebagai pendukung pembelajaran online yang menyesuaikan dengan kebutuhan pada era digitalisasi untuk menghasilkan keterampilan guru dan siswa-siswa sebagai tenaga kerja yang terampil dan berkeahlian yang mampu menyesuaikan dari tuntutan dan kebutuhan pembelajaran berbasis IT dengan mempertimbangkan nilai-nilai antara lain nilai ekonomis, nilai fungsional, nilai psikologis dan nilai kreatif dan nilai inovatif.

Program ini diharapkan dapat memberikan manfaat baik bagi siswa SMPIT Insan Rabbani dan juga kepada pendidik yang memberikan pelajaran kepada siswa di sekolah tersebut.

\section{METODE}

Pelaksanaan kegiatan pengabdian kepada masyarakat ini berbentuk pelatihan yang dilakukan secara daring melalui zoom mengenai bagaimana pemanfaatan SEVIMA EdLink sebagai pendukung pembelajaran online pada dunia pendidikan dengan metode pelatihan praktis melalui transfer ilmu dan praktek langsung pada aplikasinya melalui Webinar dengan menggunakan Zoom. Adapun tahapan yang dilalui terdiri dari :

1. Analisis kebutuhan yaitu kebutuhan training merupakan alat untuk memetakan pelatihan dan pengembangan kebutuhan pembelajaran untuk menumbuhkan bakat di tingkat manapun dalam bisnis untuk memenuhi kebutuhan bisnis di tahun mendatang.

2. Perencanaan yaitu mempersiapkan materi pelatihan, alat-alat dan bahan yang diperlukan untuk kegiatan pelatihan sebagai upaya mendukung pelayan pendidikan pembelajaran online.

3. Pelaksanaan yaitu Memberikan pengenalan kepada guru terkait optimalisasi pemanfaatan layanan SEVIMA EdLink khususnya dalam penyampaian materi- materi bahan ajarnya baik berupa file PPT, link dan juga video pembelajaran.

Kegiatan ini dilakukan pada hari Jumat 26 Juni 2020 menggunakan Zoom sebagai perantaranya. Maka tidak ada pertemuan fisik secara langsung diantara pemateri dan guru. Lokasi kegiatan ini di SMPIT Insan Rabbani Bekasi. Sasaran kegiatan ini berupa pengetahuan mengenai bagaimana mengubah bahan ajar pada kondisi normal menjadi bahan ajar daring.

\section{HASIL DAN PEMBAHASAN}

Secara umum, hasil dan luaran yang dihasilkan kegiatan ini mencakup dibentuknya sebuah kelas dengan memanfaatkan SEVIMA 
Edlink sebagai media yang memberikan pemahaman dalam penyampaian file presentasi, link, bahan teori serta vidio pembelajaran. Ditambah lagi bahwa SEVIMA Edlink dapat meningkatkan minat siswa dalam belajar. Dari beberapa hal tersebut, ada beberapa hal penting yang harus menjadi perhatian yaitu sumber tenaga sinyal di lokasi pembelajaran siswa pada berbagai kondisi dengan segala kelebihan dan kekurangan sumber daya pada lokasi siswa. Sehingga diharapkan sistem proses kegiatan belajar dan mengajar tetap bisa berjalan dalam berbagai kondisi.

Sebelum pelaksanaan, tim abdimas melakukan komunikasi ke pihak SMPIT Insan Rabbani dan Kepala Sekolah. Dari hasil diskusi tersebut, Kepala Sekolah menganjurkan untuk memberikan pelatihan yang ada kaitannya dengan Teknologi Informasi dan Komunikasi (TIK) bagi guru dengan materi yang dapat menunjang pembelajaran daring selama pandemi COVID 19. Dari hasil tersebut kami memutuskan bentuk kegiatan dengan pengenalan dan penyuluhan melalui webiner dengan menggunkan Zoom dengan memanfaatkan Teknologi dan Komunikasi (TIK) khususnya SEVIMA Edlink agar para guru dapat memahami layanan SEVIMA EdLink dalam penyampaian bahan ajarnya guna memaksimalkan kegiatan pembelajaran. Materi pelatihan yang disepakati dan sesuai dengan kebutuhan dari para guru SMPIT Insan Rabbani yaitu pengenalan layanan SEVIMA EdLink khususnya dalam pemberian bahan ajar file ppt, link maupun video pembelajaran.

\section{Pemaparan Materi Pelatihan}

Pada sesi pemaparan materi pelatihan kegiatan abdimas ini dimulai dengan melakukan tes awal pemahaman peserta terhadap materi yang akan disampaikan. Beberapa peserta banyak yang belum mendengar aplikasi SEVIMA Edlink dan juga belum menggunakan aplikasi sevima edlink. Berikut ini gambaran IPTEKS yang ditransfer dapat dijelaskan pada gambar berikut.

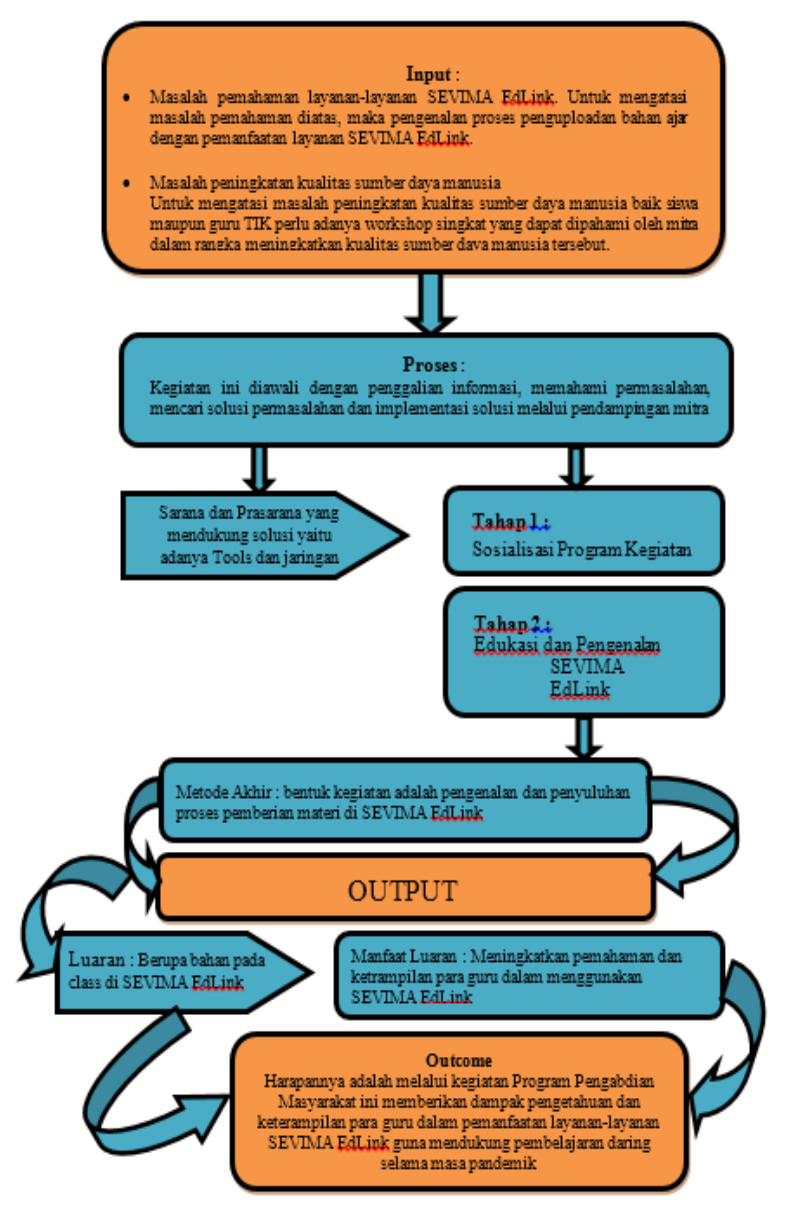

Gambar 1. Gambaran IPTEKS yang Ditransfer

Pada pemaparan materi, instruktur menjelaskan tentang pemanfaatan TIK dan faktor pendorong pembelajaran daring, Masalah pemahaman layanan-layanan SEVIMA EdLink. 
Untuk mengatasi masalah pemahaman diatas, maka pengenalan proses penguploadan bahan ajar dengan pemanfaatan layanan SEVIMA EdLink. Masalah peningkatan kualitas sumber daya manusia. Untuk mengatasi masalah peningkatan kualitas sumber daya manusia baik siswa maupun guru TIK perlu adanya workshop singkat yang dapat dipahami oleh mitra dalam rangka meningkatkan kualitas sumber daya manusia tersebut. Kegiatan ini diawali dengan penggalian informasi, memahami permasalahan, mencari solusi permasalahan dan implementasi solusi melalui pendampingan mitra. Harapannya adalah melalui kegiatan Program Pengabdian Masyarakat ini memberikan dampak pengetahuan dan keterampilan para guru dalam pemanfaatan layanan-layanan SEVIMA EdLink guna mendukung pembelajaran daring selama masa pandemik.

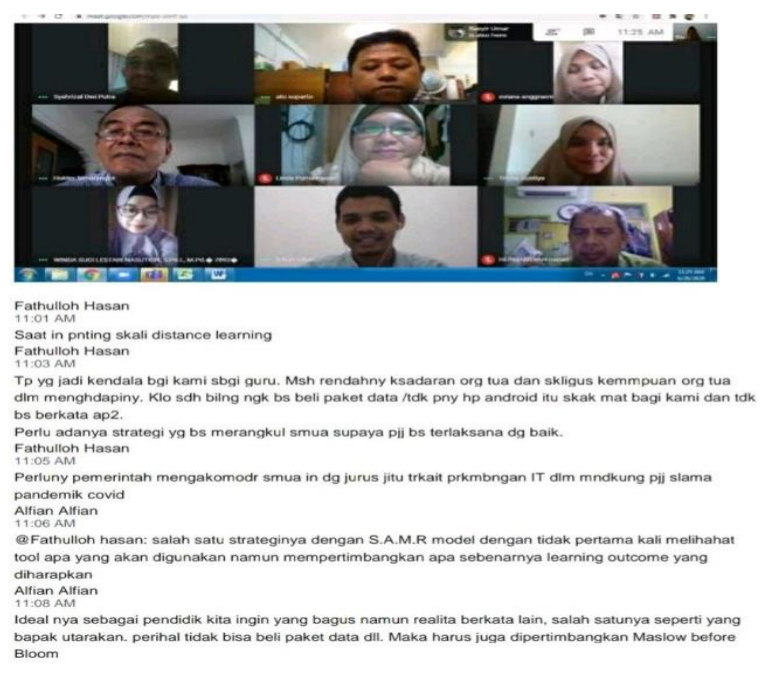

Gambar 2. Pelaksanaan Pelatihan Daring melalui Video Conference

Diskusi berlanjut tentang fitur-fitur yang dimiliki oleh SEVIMA Edlink. SEVIMA EdLink merupakan aplikasi pembelajaran online termasuk berdiskusi, video conference, atau menyelesaikan tugas dan kuis. Dilengkapi integrasi dengan SEVIMA SiAkad. Kini jarak bukan hambatan lakukan perkuliahan tatap muka secara daring dengan konferensi video. Presensi siswa cukup dengan Smartphone.

\section{Praktek Mandiri}

Setelah selesai melaksanakan pelatihan dan tutorial dari instruktur, maka dilanjutkan dengan praktek mandiri. Pada praktek mandiri ini, peserta diberikan materi berupa vidio praktek yang bertujuan agar peserta dapat melanjutkan pemahaman tentang SEVIMA Edlink dan mengimplementasikannya dengan menggunakan SEVIMA Edlink secara mandiri.

Kegiatan pengabdian masyarakat ini memberikan hasil sebagai berikut:

1. Peserta dapat memahami konsep SEVIMA Edlink.

2. Peserta dapat memahami tahapan dalam membuat kelas daring yang telah dibuat.

3. Peserta dapat memahami tahapan dalam memberikan atau mengungah materi dan tugas ke aplikasi SEVIMA Edlink.

4. Peserta dapat memahami pelaksanaan ujian secara daring dengan memanfaatkan berbagai fitur yang disediakan oleh SEVIMA Edlink. Dimana soal ujian dapat diberikan dalam berbagai tipe pertanyaan disesuaikan dengan materi pembelajaran.

5. Peserta dapat memahami cara melihat hasil atau nilai hasil ujian. 


\section{SIMPULAN}

Dari hasil evaluasi serta temuan-temuan yang kami peroleh selama pelaksanaan kegiatan pengabdian masyarakat ini, dapat kami simpulkan bahwa program pelatihan ini telah mampu memberikan manfaat yang sangat besar dan tepat sasaran bagi para guru SMPIT Insan Rabbani yang menjadi khalayak sasaran dalam kegiatan ini. Bentuk pelatihan seperti ini merupakan bentuk yang sangat efektif untuk memberikan menambah pengetahuan serta ketrampilan baru khususnya pemanfaatan aplikasi SEVIMA EdLink guna mendukung pembelajaran daring selama masa pendemik ini. Para guru sangat antusias dalam mengikuti penyuluhan terkait pemahaman layananlayanan yang ada di SEVIMA EdLink terutama saat membuat kelas dan memberikan materi-materi bahan ajarnya baik berupa file PPT, link dan juga video pembelajaran sehingga memudahkan para siswanya dalam menerima materi-materinya melalui laptop maupun smartphone tanpa harus melakukan instalasi.

\section{UCAPAN TERIMA KASIH}

Penulis mengucapkan terima kasih kepada Kepala Sekolah SMPIT Insan Rabbani yang telah memberikan bantuan dalam pengumpulan data hingga terlaksananya pelatihan, sehingga pengabdian masyarakat ini dapat diselesaikan dengan baik.

\section{DAFTAR PUSTAKA}

Arifin, Syamsul. 2013. "Panduan Pengembangan Dan Penyelenggaraan Kuliah Daring Indonesia Terbuka \& Terpadu." Buku Pembelajaran Daring 1 (1): 1-159.
Kharisma, Novia Nur, Maria Veronika Roesminingsih, and Suhanadji Suhanadji. 2020. "Gambaran Kebutuhan Pembelajaran Daring Pkbm Budi Utama Surabaya Pada Masa Pandemi Covid-19." Jurnal Pendidikan Nonformal 15 (1): 38-44.

Marlina, Emas. 2020. "Pengembangan Model Pembelajaran Blended Learning Berbantuan Aplikasi Sevima Edlink." Jurnal Padegogik 3 (2): 104-10.

Wibowo, Andi, and Indah Rahmayanti. 2020. "Penggunan Sevima Edlink Sebagai Media Pembelajaran Online Untuk Mengajar Dan Belajar Bahasa Indonesia" 02 (2): 163-74. https://doi.org/10.29405/imj.v2i2.

Zukri, Pajri Al, Ellin Asynari, and Nurbo Jatmiko. 2020. "Standar Kelengkapan Fitur E-Learning Supply Chain Management Pada Produk Backlog Menggunakan Metodologi Scrum.' $\begin{array}{llll}\text { Sistemasi } & 9 & \text { (3): } & 419 .\end{array}$ https://doi.org/10.32520/stmsi.v9i3.738. 